\title{
Management of Urban Mobility to Control Climate Change in Cities in Spain
}

\author{
Natalia Sobrino and Andres Monzon
}

\begin{abstract}
The need to decarbonize urban mobility is one of the main motivations for all countries to achieve reduction targets for greenhouse gas (GHG) emissions. In general, the transport modes that have experienced the most growth in recent years tend to be the most polluting. Most efforts have focused on improvements in vehicle efficiency and on the renewal of vehicle fleets; more emphasis should be placed on strategies related to the management of urban mobility and modal share. Research of individual travel that analyzes carbon dioxide $\left(\mathrm{CO}_{2}\right)$ emissions and car and public transport share in daily mobility will enable better assessments of the potential of urban mobility measures introduced to limit GHG emissions produced by transport in cities. The climate change impacts of daily mobility in Spain are explored with data from two national travel surveys in 2000 and 2006, and a method for estimating the $\mathrm{CO}_{2}$ emissions associated with each journey and each surveyed individual is provided. The results demonstrate that from 2000 to 2006 , daily mobility has increased and has led to a $17 \%$ increase in $\mathrm{CO}_{2}$ emissions. When these results are separated by transport mode, cars prove to be the main contributor to that increase, followed by public transport. More focus should be directed toward modal shift strategies, which take into account not only the number of journeys but also the distance traveled. These contributions have potential applications in the assessment of current and future urban transport policies related to low-carbon urban transportation.
\end{abstract}

Transport is widely recognized to be one of the most significant sources of greenhouse gas (GHG) emissions-particularly carbon dioxide $\left(\mathrm{CO}_{2}\right)$ emissions, which are directly related to the consumption of carbon-based fuel - and the greenhouse effect is regarded as one of the most serious threats to the environment today. In 1997, the Kyoto Protocol highlighted the transport sector as key to achieving its target (1). Global $\mathrm{CO}_{2}$ emissions from transport represented $22.5 \%$ of global $\mathrm{CO}_{2}$ emissions in 2008 in Organisation for Economic Co-operation and Development countries and have increased by $44 \%$ from 1990 to 2008 (2). Car dependence has been identified as the main reason for this increase in transport emissions. Crucially, many countries are experiencing an economic recession that has affected transport activity, most noticeably freight (2). Consequently, transport emissions are decreasing slightly.

In Spain specifically, transport emissions increased by $70 \%$ from 1990 to 2009, reaching a total of 94.5 million tons of $\mathrm{CO}_{2}$ (3). As

\footnotetext{
N. Sobrino, Transport Research Center, and A. Monzon, Transport Department, Universidad Politécnica de Madrid, ETSI de Caminos, Canales, y Puertos, Profesor Aranguren s/n, 28040 Madrid, Spain. Corresponding author: N. Sobrino, natalia.sobrino@upm.es.
}

Transportation Research Record: Journal of the Transportation Research Board, No. 2375, Transportation Research Board of the National Academies, Washington, D.C., 2013, pp. 55-61.

DOI: $10.3141 / 2375-07$ motorized modes are favored over other forms of transport, road transportation is the main energy consumption mode and, consequently, the main transportation pollutant source at $80 \%$ of the total transport energy demand (4). Passenger emissions are rising more rapidly than freight transport emissions, caused by an overall increase in daily mobility. These numbers put into perspective the need to set specific emissions targets for passenger mobility and to develop policies aimed at cohesive and concrete emissions reductions in passenger transport (5).

Local mobility is important, because $40 \%$ of all transport-related $\mathrm{CO}_{2}$ is emitted in cities. The need to decarbonize urban mobility is a priority if countries are to achieve reduction targets for GHG emissions. Moreover, the car is the main mode: $75 \%$ of all kilometers traveled (passenger kilometers) in European urban areas are produced by car journeys (6). The public transport mode share is decreasing almost everywhere and now accounts for only $16 \%$ of journeys (6). To achieve reduction targets for GHG emissions, more emphasis must be placed on modal split policies that highlight public transport and nonmotorized transport as viable options. For instance, Lapillonne et al. report that public transport is four times more energy-efficient than cars (7). Moreover, where rail infrastructures and bus lanes are available, public transport can compete with cars because of its efficiency and the fact that travel times during peak hours tend to favor public transport users. Overall, public transport offers a better level of service, mainly because of its regularity and reduced travel times.

A shift is required in both travel behavior and the perception of public transport as an unsafe, time-consuming, inconvenient option among populations accustomed to traveling by car (8). A European Union white paper sets challenging targets for a shift to more sustainable modes in urban transportation in European countries, encouraging cities to increase the modal share of nonmotorized modes (9). Modal shift policies are consistently among the best practices in urban areas for reducing the environmental effects of urban transport. Rail modes are seen as an ecological form of transportation (10). Buses offer flexibility, can be used quickly in response to changing demand, and do not need specialized infrastructure, unlike trains (11). Walking and cycling are carbonless, environmentally friendly solutions for individual urban transport (12). In Europe, cycling and walking account for approximately $13 \%$ of urban passenger kilometers (13).

In Spain, motorized modes are favored over other forms of transport, and much investment is made in new road infrastructure in dense urban areas. Moreover, Spanish daily commute patterns indicate that the population is slowly reverting from public transport to carbon-intensive automobile transport (5). However, the difference in the use of public transport in large and small urban areas is significant. In dense cities, travelers are more likely to use public transport; in Madrid, Barcelona, and Bizkaia, 20\% to $30 \%$ of trips involve public transport, whereas the share of public transport is $5 \%$ to $11 \%$ in small urban areas. Notably, a significant percentage (30\% to $45 \%$ ) of daily journeys in Spain are made on foot (14). 
The goals of this paper are to investigate whether mobility patterns are evolving toward a low-carbon urban transport. To this end, the study aims to explore the influence of modal share on climate change impacts by providing an overview of Spanish daily mobility trends from 2000 to 2006. The research focuses on passenger trips and considers daily travel time, distance, and $\mathrm{CO}_{2}$ emissions. The analysis will enable better assessment of the potential of future urban mobility measures to limit GHG emissions produced by transport in cities. This research has potential applications in the evaluation of current and future urban transport policies to promote better mobility management in cities.

The paper is structured as follows. First, the data set and the method used to estimate $\mathrm{CO}_{2}$ emissions linked to passenger transport from Spanish national travel surveys (NTSs) are presented. Then, car and public transport share in daily mobility and the evolution of this indicator over time are analyzed in general. The average daily emissions per passenger are presented, and car and public transport use are analyzed with a view toward climate change impacts. Finally, an analysis of modal share shows that measures must be taken at a local level, related to low-carbon urban transport, to reach climate change targets.

\section{DATA AND METHODOLOGY}

\section{Household Mobility Survey Data}

Urban transportation management must become familiar with urban mobility patterns. NTSs have become key tools for analyzing mobility patterns to formulate national-level policy recommendations. Some studies have been conducted that make use of this resource. Stead analyzes the impact and trends of transport emissions in Britain by using the 1989-1991 NTS to recommend certain transport policies and finds that measures to increase occupancy and manage transport capacity are required to attain maximum reductions in vehicle emissions (15). Nicolas and David highlight the relevance of using NTSs to analyze individual trip behavior and to better consider environmental transport policies; French daily mobility remains car-based, and policies that affect car fleet mix and its technology have been suggested to combat the climate change impacts that occur as a result (16). Travel behavior and transport fuel use were studied in the Netherlands and the United Kingdom, where in recent decades, travel patterns in both countries have more or less remained the same while individual $\mathrm{CO}_{2}$ emissions per capita have increased (17). Fewer than one-half of all journeys in the Netherlands and less than two-thirds of all journeys in the United Kingdom are made by car. Results show that car availability is consistently the most significant predictor of individual $\mathrm{CO}_{2}$ emissions, and its influence on emissions has increased over time.

The Spanish Ministry of Transport and Public Works developed a survey of the mobility of residents (MOVILIA) to provide an overall view of mobility and its main patterns in Spain. The daily mobility survey requested information regarding trip origin and destination, travel mode, departure and arrival times, and trip purpose for 1 working day and 1 weekend day. In addition, information about individuals in households was gathered, including location of residence, gender, age, income, car ownership status, and occupation. Surveys were conducted in 2000 and 2006 with the same trip definition, sampling method, and survey mode $(18,19)$. The 2006 data describe some 230,000 trips made by more than 49,000 people.

The two surveys do have some differences. For example, the geographic scope of the 2000 survey allows for data to be separated only by region, whereas the 2006 survey is broken down by province. Also, up to four members of each household were surveyed in 2000, but only one individual per household was surveyed in 2006. These changes were introduced because, despite the larger number of individuals in the 2000 sample, the number of trips was not clearly defined. Finally, walking trips of less than 10 min were excluded in 2000, whereas only walking trips of less than 5 min were excluded in 2006 (Table 1).

\section{Estimating $\mathrm{CO}_{2}$ Emissions for Urban Trips}

The $\mathrm{CO}_{2}$ emissions per passenger (in $\mathrm{g} \mathrm{CO}_{2}$ /passenger trip) are calculated by multiplying the average emissions factor for each aggregated transport mode $i\left(\mathrm{EF}_{i}\right)$ in grams $\mathrm{CO}_{2} /$ (passenger kilometer) by the trip distance (Dt) (in kilometers) as follows (15-17, 20):

$$
\begin{aligned}
& \mathrm{CO}_{2} \text { emissions per passenger } \\
& \qquad=\mathrm{EF}_{i}\left(\text { in grams } \mathrm{CO}_{2} / \text { passenger kilometer }\right) \times \mathrm{Dt}
\end{aligned}
$$

As a first step, the $\mathrm{CO}_{2}$ emissions factor is estimated for each mode of transport considered in the survey. The MOVILIA survey data serves as a source of information with which to estimate the $\mathrm{CO}_{2}$ emissions per passenger trip by applying the emissions factors of each transport mode. Each trip recorded in the survey (from the available information) contains characteristics about the individual, travel time, transport mode, and more. The main indicators that could be obtained from MOVILIA are the number of trips and total travel time per passenger per day, which are broken down by day of the week (workday or weekend day), transport mode, purpose, and age class. One issue with MOVILIA data is the lack of information about trip distance, and transport modes are aggregated in groups according to $(a)$ walking and cycling (soft modes), (b) car and motorcycle, $(c)$ urban bus and metro, $(d)$ interurban bus, $(e)$ train, and $(f)$ other (taxis, collective company transport, and so on). The proposed method for estimating the $\mathrm{CO}_{2}$ emissions per passenger trip is charted in Figure 1.

For cars and motorcycles, the vehicle emissions factors are applied from the EMEP/EEA [Cooperative Programme for Monitoring and Evaluation of the Long-Range Transmission of Air Pollutants in Europe (EMEP) and European Environment Agency (EEA)] guidebook to European emissions, which is used to estimate emissions factors and relevant activity data to calculate exhaust emissions for different vehicle types, which have their own equations according to age, fuel type, and operating speed (21). ENERTRANS results for Spain indicate that average speeds of 40 and $35 \mathrm{~km} / \mathrm{h}$ have been used for cars and motorcycles, respectively (22).

The average emissions factor per passenger for each year (2000 and 2006) was estimated for cars and motorcycles by introducing the occupancy rate and activity demand by vehicle type from the database of TREMOVE, a transport and emissions simulation model developed for the European Commission (23). For urban and interurban buses, the same approach based on the EMEP/EEA method is applied, taking into account the urban driving mode for urban buses. For rail-based modes, emissions factors were obtained from previous studies that estimate emissions factor data for rail modes in Spain (24). Because different transport modes are aggregated in the survey (e.g., urban bus and metro), an aggregation factor for each mode of transport is applied in such cases according to demand (passengers per kilometer by each mode of transport from the TREMOVE database). Finally, the other category aggregates various other modes of transport, including taxis and collective company transport. The 
TABLE 1 Technical Characteristics of MOVILIA, 2000 and 2006

\begin{tabular}{lll}
\hline Characteristic & MOVILIA 2000 & MOVILIA 2006 \\
\hline Main body involved & Ministry of Transport & Ministry of Transport \\
Statistical unit & Household & Household \\
Household members & All (up to 4 people) & 1 \\
Individuals excluded & No age limit & No age limit \\
from survey & Movement from origin to destination for & Movement from origin to destination for \\
Trip definition & a main purpose & a main purpose \\
& The main mode is either a stated main & The main mode is either a stated main \\
Main mode definition & mode or determined by following a & mode or determined by following a \\
& mode hierarchy for public transport & mode hierarchy for public transport \\
& (train $>$ metropolitan bus $>$ metro & (train $>$ metropolitan bus $>$ metro \\
& $>$ urban bus) $>$ car passenger $>$ car & urban bus) $>$ car passenger $>$ car \\
driver $>$ bicycle $>$ on foot
\end{tabular}

NOTE: CAPI = computer-assisted personal interviewing; $\mathrm{NA}=$ data not available.

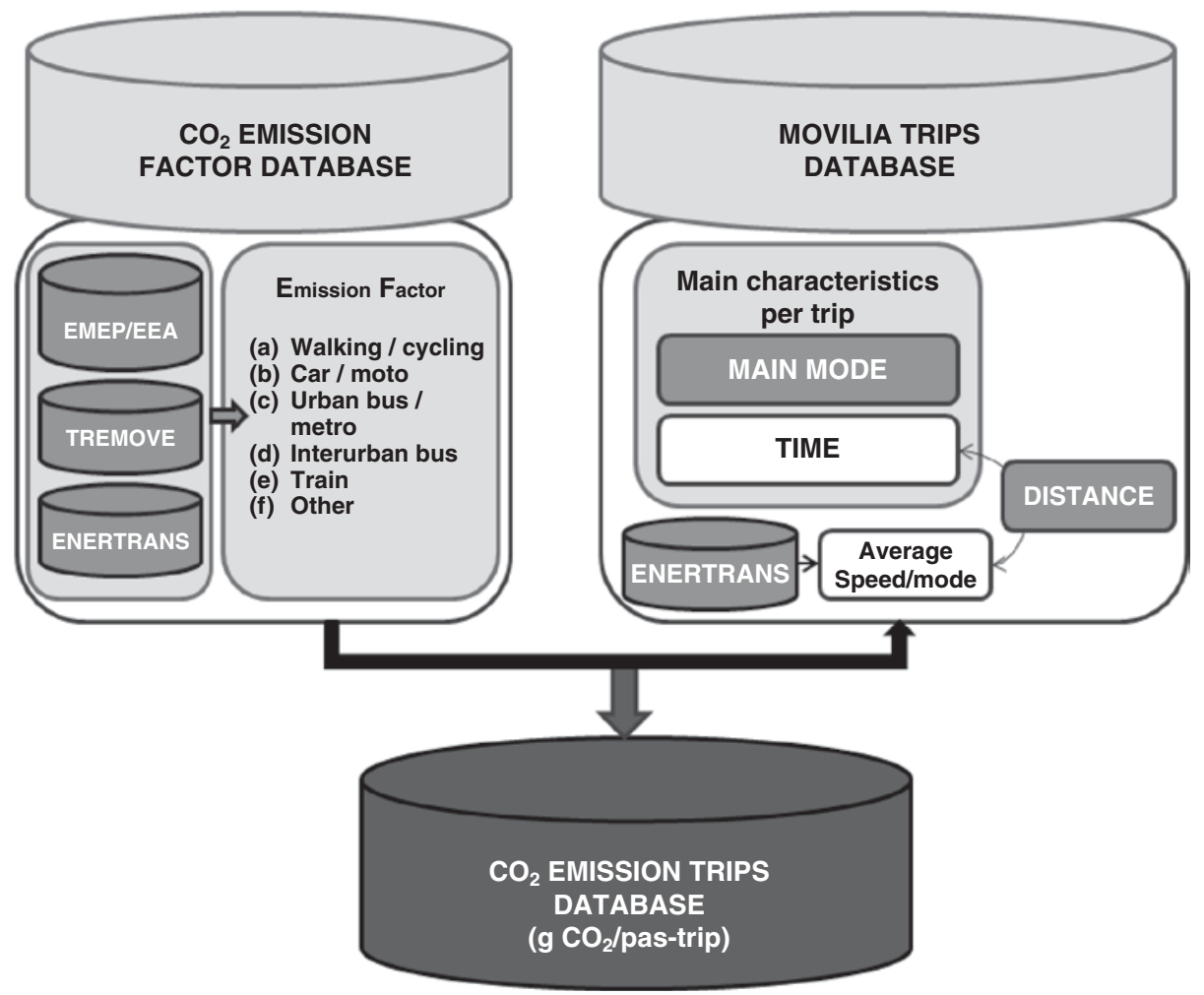

FIGURE 1 Method for estimating $\mathrm{CO}_{2}$ emissions per passenger (pas) trip in MOVILIA survey (moto $=$ motorcycle). 


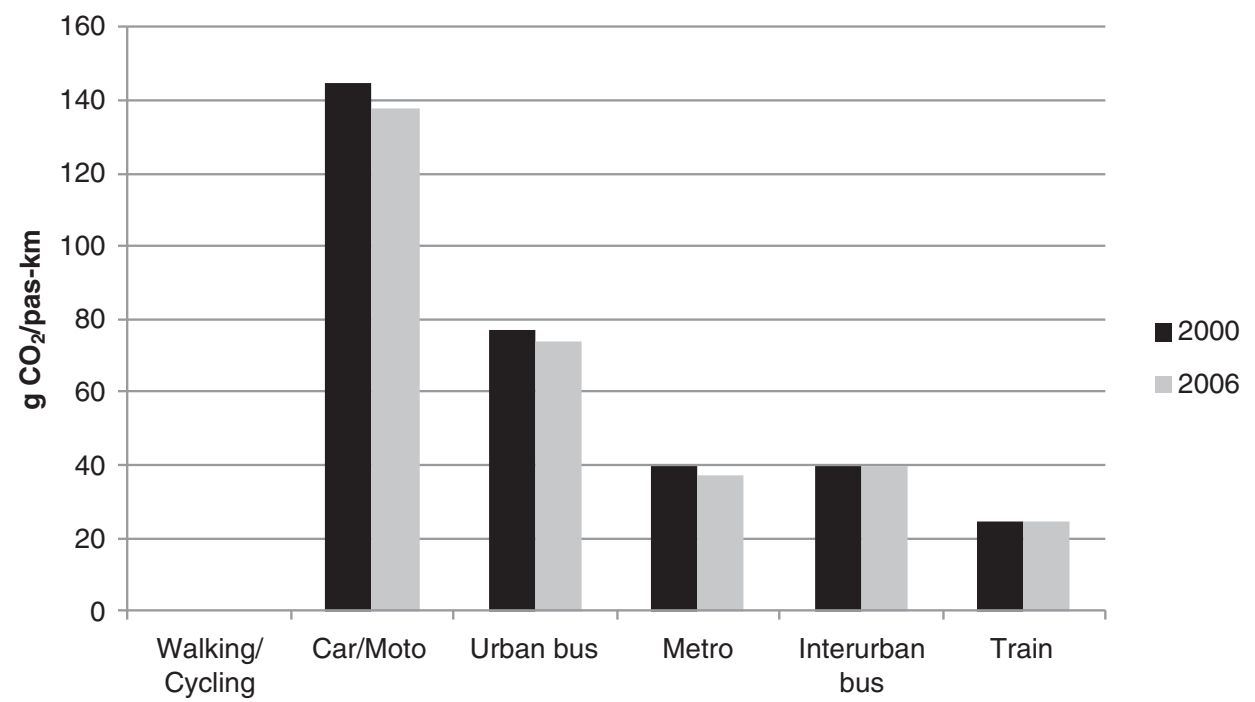

FIGURE 2 Average $\mathrm{CO}_{2}$ emissions for main urban mobility modes in Spain (pas = passenger).

emissions factor for this case is calculated on the basis of aggregated average emissions factors of the different transport modes.

The second step is focused on the indirect calculation of trip distance. The ENERTRANS project provides real average speed data for the different transport modes in Spain (22). These data and trip times from MOVILIA are used to calculate the trip distance $(18,19)$. Finally, the $\mathrm{CO}_{2}$ emissions per passenger and trip are calculated with Equation 1.

Figure 2 shows average $\mathrm{CO}_{2}$ emissions per passenger kilometer for each mode. Private cars and motorcycles produce the most $\mathrm{CO}_{2}$ emissions. The trend toward more efficient vehicles in the vehicle fleet accounts for the slight decrease in average emissions from 2000 to 2006 .

\section{URBAN MOBILITY TRENDS}

\section{Analysis of Car and Public Transport Use}

Mobility patterns are analyzed in this section, with a focus on transport mode. The environmental impact of transport is strongly determined by overall transport activity and modal split. The 2000 and 2006 MOVILIA surveys are compared, and information is provided to aid understanding of the results of the following section.

One of the important variables that influence the modal split is household car availability (17). In 2006, 31.6\% of Spanish households had more than one vehicle with which to make journeys, whereas in 2000, this figure was only $27.6 \%$ - a difference of four percentage points (Figure 3 ). This shift likely has contributed to the increase in car trips and, consequently, to the rise in $\mathrm{CO}_{2}$ emissions from urban mobility in Spain. The average number of trips per passenger per day on a working day was higher in 2006 (3.3 trips/day) than in 2000 (2.9 trips/day) (Table 2). Considering only people traveling on working days, the average travel time increased slightly from $71 \mathrm{~min}$ in 2000 to $73 \mathrm{~min}$ in 2006.

Finally, as expected, the car is the main motorized mode used by Spanish travelers for daily mobility. Moreover, car use was higher in 2006 than in 2000, to the detriment of public transport use. Still, the share of walking trips in Spanish cities is rather high (accounting for more than $40 \%$ of the trips), and public transport patronage accounts for about $10 \%$. These figures influence the transfer potential of trips among transport modes. In addition, a recent study that measured mobility patterns in areas of Spain with investment in new public transport infrastructure reports that in many such cases, a positive effect has been observed on the modal shift from private- to public-based modes (25).

In summary, Spanish daily mobility increased and moved toward a more car-dependent lifestyle from 2000 to 2006. People are making more and longer journeys, and the use of public transport is decreasing. As a result, more research into the climate change impacts of daily mobility and more strategies focused on managing daily mobility will be needed to achieve targets for sustainable mobility in cities.

\section{Modal Split and Climate Change Impacts}

The level of $\mathrm{CO}_{2}$ emissions per individual trip depends on transport mode and distance traveled in each mode or total trip time. According to individual $\mathrm{CO}_{2}$ emissions calculated from Spanish NTS data

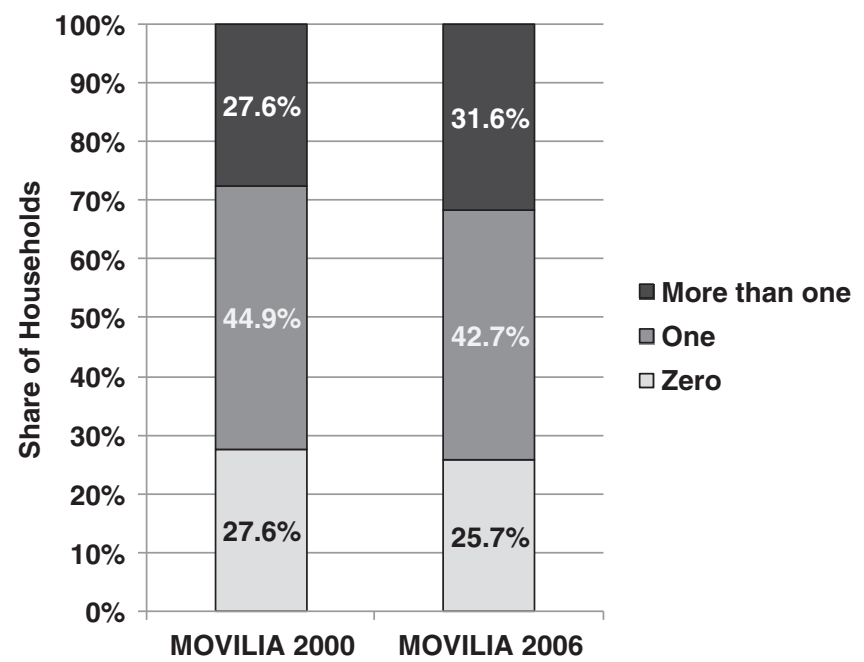

FIGURE 3 Share of households with one or more private vehicles. 
TABLE 2 Main Results per Individual on Working and Weekend Days

\begin{tabular}{lcc}
\hline Parameter & MOVILIA 2000 & MOVILIA 2006 \\
\hline Sample size, household & 23,635 & 49,027 \\
Sample size, individuals & 62,473 & 49,027 \\
Working day & & 83.5 \\
$\quad$ Individuals who travel (\%) & 65.5 & 3.3 \\
$\quad$ No. of trips (average of & 2.9 & 73 \\
$\quad$ individuals who travel) & & \\
$\quad$ Average travel time (min) & 71 & 2.9 \\
Weekend day & & 80 \\
$\quad$ Individuals who travel (\%) & 51.1 & \\
$\quad$ No. of trips (average of & 2.5 & 81.3 \\
$\quad$ individuals who travel) & & 18.7 \\
$\quad$ Average travel time (min) & 76 & \\
Use of mechanical modes & & \\
$\quad$ Car or motorcycle (\%) & 79.4 & \\
Public transport (\%) & 20.6 & \\
\hline
\end{tabular}

NoTE: No. $=$ number.

for 2000 and 2006, private vehicles (cars and motorcycles) are the highest producers of $\mathrm{CO}_{2}$ emissions in Spain for both years. Figure 4 displays the shares of private vehicles and public transport in the number of trips, travel times, and $\mathrm{CO}_{2}$ emissions for both years.

A comparison of private vehicle and public transport data provided the following results. The slight increase in the number of trips made by private vehicles has led to a decrease in public transport use (about 6 percentage points) from 2000 to 2006 . However, the time spent traveling each day in private vehicles and public transport remains constant over that period, indicating that unless the number of trips by public transport has decreased, the time spent on each trip has increased and, consequently, the $\mathrm{CO}_{2}$ emissions have not been significantly reduced. The number of trips made by private vehicles has increased and time spent traveling has increased slightly; thus, the travel time per trip made by private vehicle in 2006 is shorter than in 2000. Nevertheless, the increased number of private vehicle trips signifies an overall increase in $\mathrm{CO}_{2}$ emissions over the period.

Soft modes have been excluded from this analysis because of differences in the two Spanish NTSs: walking trips of less than 10 min were excluded in 2000, whereas only those of less than 5 min were excluded in 2006. Still, the number of trips by soft modes represents an important share in Spanish urban mobility—around $40 \%$ of trips made by all transport modes.

Results of applying the proposed method and comparing the evolution from 2000 to 2006 (calculated as a percentage increase since 2000) are listed in Table 3. Soft modes are not compared because of the different definitions of soft mode trips in the two surveys. In the impact assessment section of the table, indicators reflect changes from 2000 to 2006: $(+)$ is a slight increase, $(++)$ is moderate increase, $(-)$ is a slight decrease, and (--) is a measured decrease. Results were obtained for an average day (including workdays and weekend days).

Generally, the increase in Spanish daily travel has led to increased GHG emissions in cities, where total $\mathrm{CO}_{2}$ emissions have risen by $17.08 \%$. Unless the total number of daily journeys has decreased, public transport trips have gotten longer, which increases $\mathrm{CO}_{2}$ emissions. The private vehicle share in daily mobility has increased by $9.2 \%$ in number of trips and by $25.1 \%$ in travel time with respect to 2000 levels. The main consequence is that private vehicles are the main contributor to the growth of total $\mathrm{CO}_{2}$ emissions associated with

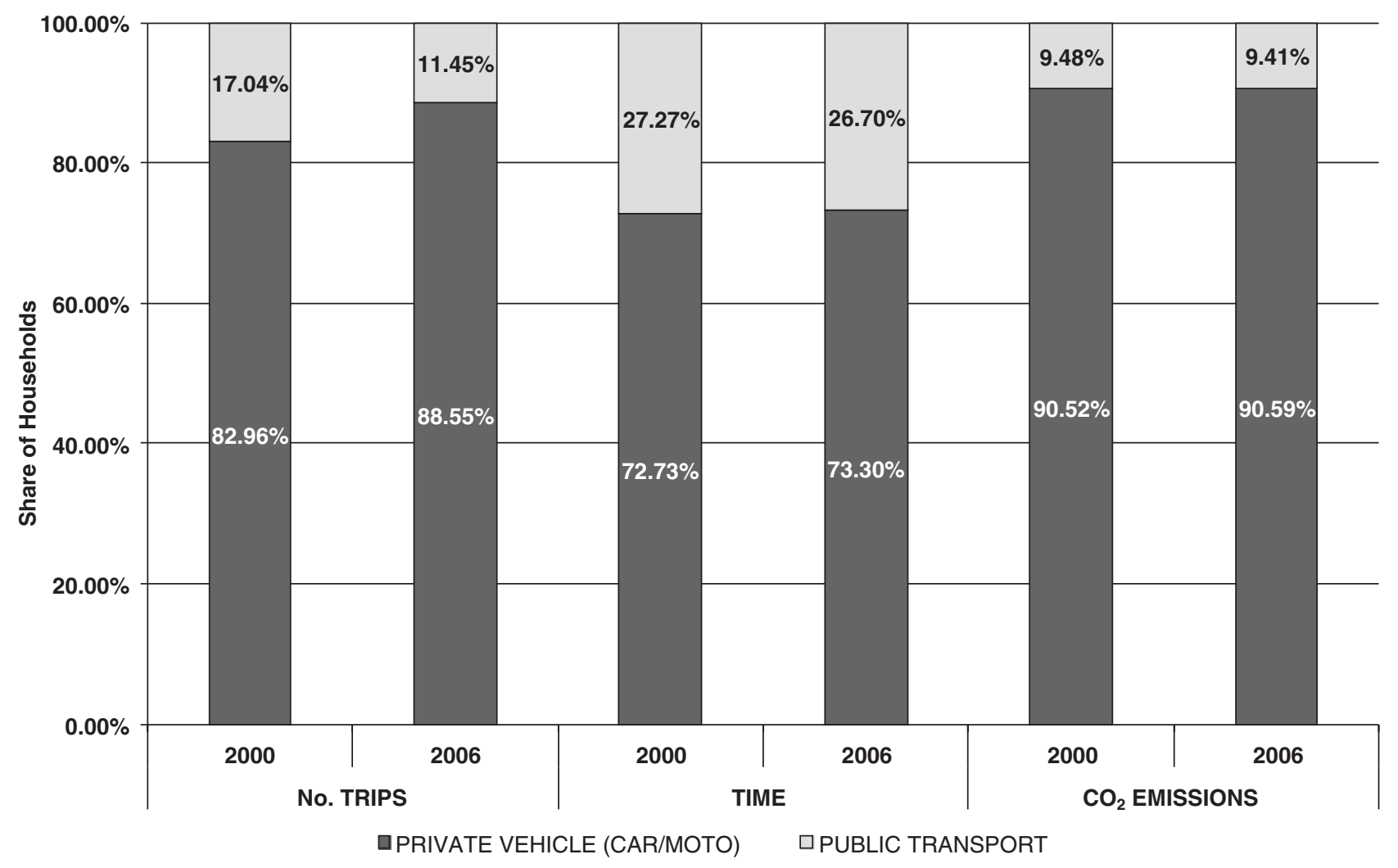

FIGURE 4 Share by private vehicle and public transport in the number of trips, time, and $\mathrm{CO}_{2}$ emissions for 2000 and 2006. 
TABLE 3 Trends in Modal Split and $\mathrm{CO}_{2}$ Emissions per Traveler on an Average Day

\begin{tabular}{|c|c|c|c|c|c|}
\hline Parameter & Soft Modes & $\begin{array}{l}\text { Car or } \\
\text { Motorcycle }\end{array}$ & $\begin{array}{l}\text { Public } \\
\text { Transport }\end{array}$ & Other & Total \\
\hline \multicolumn{6}{|l|}{ Number of trips } \\
\hline 2000 & 0.83 & 1.09 & 0.22 & 0.08 & 2.22 \\
\hline 2006 & 1.44 & 1.19 & 0.15 & 0.06 & 2.84 \\
\hline$\Delta \%$ & - & 9.2 & -31.8 & -25.0 & - \\
\hline \multicolumn{6}{|l|}{ Time (min) } \\
\hline 2000 & 15.30 & 19.59 & 7.34 & 1.91 & 44.14 \\
\hline 2006 & 24.84 & 24.51 & 8.93 & 1.89 & 60.16 \\
\hline$\Delta \%$ & - & 25.1 & 21.7 & -1.0 & - \\
\hline \multicolumn{6}{|c|}{$\mathrm{CO}_{2}$ emissions $\left(\mathrm{g} \mathrm{CO}_{2} /\right.$ day $)$} \\
\hline 2000 & 0.00 & $1,797.45$ & 188.32 & 180.42 & 2,166 \\
\hline 2006 & 0.00 & $2,142.75$ & 222.52 & 170.95 & 2,536 \\
\hline$\Delta \%$ & - & 19.2 & 18.2 & -5.2 & 17.1 \\
\hline \multicolumn{6}{|l|}{ Impact assessment } \\
\hline Trips & - & $(+)$ & $(--)$ & $(--)$ & - \\
\hline Time & - & $(++)$ & $(+)$ & $(-)$ & - \\
\hline $\mathrm{CO}_{2}$ emissions & - & $(+)$ & $(+)$ & $(-)$ & $(+)$ \\
\hline
\end{tabular}

NoTE: $-=$ data not comparable because of differences in survey definitions.

daily mobility in Spain. Soft modes have attracted a high rate of trips over the same period; nevertheless, it has not been enough to stop the increase in $\mathrm{CO}_{2}$ emissions.

In summary, the public transport share must be improved by making it more competitive with private vehicles in cities. For example, Monzon et al. find that even though Madrid has a good supply of public transport, the car is still an attractive option in urban areas and the time spent (26). Improved management of public transport infrastructure is key to reducing the use of private vehicles and, consequently, the climate change impacts in cities.

\section{CONCLUSIONS}

In Spain, emissions per passenger are rising rapidly as a result of increased daily mobility. More effort must be made to prevent the associated climate change impacts. Modal split trends and their relationship to climate change impacts were analyzed. A relevant evaluation based on NTSs was applied to Spanish daily mobility in 2000 and 2006 to assess the global contribution of daily mobility to climate change. The changes in car and transit use during that period were analyzed. The findings could be useful for transport planners to design effective policies for changing the mobility trends to meet the reduction targets for $\mathrm{CO}_{2}$ emissions.

$\mathrm{CO}_{2}$ emissions per passenger trip were estimated from Spanish NTS data by applying emissions factors for each transport mode. The $\mathrm{CO}_{2}$ emissions per passenger and trip were calculated by multiplying trip distance by the emissions factor for each aggregated transport mode. The trend toward more efficient vehicles in the fleet accounted for the slight decrease in passenger-kilometer emissions from 2000 to 2006, but current efforts to improve vehicle technology and fuel efficiency are not enough to meet emissions reduction targets in cities.

Results of this analysis reveal that in Spain from 2000 to 2006, daily mobility has increased and $\mathrm{CO}_{2}$ emissions have increased by 17\%; car use is the main culprit. More focus must be directed toward public transport, which is key to decarbonizing urban mobility. Nevertheless, this strategy is somewhat limited; some studies of Madrid suggested that only $18 \%$ of trips currently made by car could be made by other modes, respecting trip time conditions and without affecting their characteristics (27). Distance also is an important issue to be taken into account (15). However, sustainable mobility in cities begins with better integration of policies that aim to coordinate environmental, economic, and social considerations. The results of this study indicate that a modal shift in cities may play a role in the process of stabilizing the carbon footprint of urban mobility. Furthermore, low-carbon and energy-efficiency strategies should focus not only on long-distance trips but also on urban movements, which account for $40 \%$ of emissions and have been increasing over time.

\section{ACKNOWLEDGMENTS}

The authors thank the Spanish Ministry of Development, especially Juan Manuel Ropero, for providing data from MOVILIA 2000 and 2006. The authors also thank the anonymous reviewers whose specific, insightful comments greatly contributed to the clarity of this paper.

\section{REFERENCES}

1. Breidenich, C., D. Magraw, A. Rowley, and J. W. Rubin. The Kyoto Protocol to the United Nations Framework Convention on Climate Change. The American Journal of International Law, Vol. 92, No. 2, 1998, pp. 315-331.

2. Reducing Transport Greenhouse Gas Emissions: Trends and Data. 2010. International Transport Forum, Organisation for Economic Co-operation and Development, Paris, 2010.

3. Greenhouse Gas Emissions, by Source. EUROSTAT, Luxembourg, Luxembourg. http://appsso.eurostat.ec.europa.eu/nui/show.do?dataset= env_air_gge\&lang=en. Accessed July 2012.

4. Balances Energéticos Anuales. Período: 1990-2010. Instituto para la Diversificación y Ahorro de la Energía, Madrid, Spain. www.idae.es/ index.php/id.481/mod.pags/mem.detalle. Accessed July 2011.

5. Mendiluce, M., and L. Schipper. Trends in Passenger Transport and Freight Energy Use in Spain. Energy Policy, Vol. 39, No. 10, 2011, pp. 6466-6475.

6. Flaush, A. Decarbonization and Future Energy Forms in Transport. Presented at Transport Research Arena Conference, Athens, Greece, 2012.

7. Lapillonne, B., C. Sebi, and K. Pollier. Energy Efficiency Trends in the Transport Sector in the EU: Lessons from the ODYSSEE MURE Project. Agence de l'Environnement et de la Maîtrise de l'Energie, November 
2012. http://www.odyssee-indicators.org/publications/PDF/transportenergy-efficiency-trends.pdf. Accessed December 2012.

8. Tiwari, R., R. Cervero, and L. Schipper. Driving $\mathrm{CO}_{2}$ Reduction by Integrating Transport and Urban Design Strategies. Cities, Vol. 28, No. 5, 2011, pp. 394-405.

9. Roadmap to a Single European Transport Area: Towards a Competitive and Resource Efficient Transport System. COM/2011/0144. European Commission, Brussels, Belgium, 2011.

10. Bonnafous, A., and C. Raux. Transport Energy and Emissions: Rail. In Handbooks in Transport 4: Handbook of Transport and the Environment (D. A. Hensher and K. J. Button, eds.). Emerald Group Publishing, Elsevier, Boston, Mass., 2003, pp. 293-308.

11. The Future of Transport: A Network for 2030. Department for Transport, London, July 2004.

12. Chapman, L. Transport and Climate Change: A Review. Journal of Transport Geography, Vol. 15, No. 5, 2007, pp. 354-367.

13. European Environment Agency. Laying the Foundations for Greener Transport TERM 2011: Transport Indicators Tracking Progress Towards Environmental Targets in Europe. Office for Official Publications of the European Union, Luxembourg, Luxembourg, 2011.

14. Cascajo Jiménez, R., A. Monzon de Cáceres, and P. Jordá Lope. Análisis de la Movilidad Metropolitana Española en el Quinquenio 2002-2006. Presented at 8th Congreso de Ingeniería del Transporte, A Coruña, Spain, 2008.

15. Stead, D. Relationships Between Transport Emissions and Travel Patterns in Britain. Transport Policy, Vol. 6, No. 4, 1999, pp. 247-258.

16. Nicolas, J., and D. David. Passenger Transport and $\mathrm{CO}_{2}$ Emissions: What Does the French Transport Survey Tell Us? Atmospheric Environment, Vol. 43, No. 5, 2009, pp. 1015-1020.

17. Stead, D., and Y. O. Susilo. Recent Trends in Travel Behavior and Passenger Transport Fuel Use: A Comparison of the Netherlands and the United Kingdom. Proc., EuroCities-DATTA Workshop Urban Mobility in Europe, Impacts of Fuel Price on Car Use, Namur, Belgium, 2009. http://www.eurocities-datta.eu/documents/stead_paper.pdf. Accessed July 2012.

18. Encuesta de Movilidad de las Personas Residentes en España, MOVILIA 2000/2001. Ministerio de Fomento, Madrid, Spain, 2001.
19. Encuesta de Movilidad de las Personas Residentes en España, MOVILIA 2006/2007. Ministerio de Fomento, Madrid, Spain, 2007.

20. Anable, J., B. Boardman, and A. Root. Travel Emission Profiles: A Tool for Strategy Development and Driver Advice. Environmental Change Unit, University of Oxford, Oxford, United Kingdom, 1997.

21. European Monitoring and Evaluation Programme, European Environment Agency. EMEP/EEA Air Pollutant Emission Inventory Guidebook-2009. Technical Guidance to Prepare National Emission Inventories. Technical Report 9/2009. Office for Official Publications of the European Union, Luxembourg, Luxembourg, 2009.

22. Cillero, A., P. Bouzada, A. Garcia Alvarez, and M. Martin Cañizares. Metrics and Standardization of Consumption and Emissions in Transport. ENERTRANS Project Documents, Vol. 6, 2008. http://www.investigacionffe.es/documentos/enertrans/EnerTrans_Estandardizaci\%C3\%B3n_ Consumos.pdf. Accessed July 2012.

23. TREMOVE, version 3.3. Transport \& Mobility Leuven, Louvain, Belgium, 2010. http://www.tremove.org.

24. Guía Práctica para el Cálculo de las Emisiones de Gases de Efecto Invernadero (GEI). Oficina Catalana del Canvi Climàtic, Barcelona, Spain, March 2012.

25. Comendador, J., F. Di Ciommo, and M. E. López-Lambas. HABIT o Cómo Medir la Subjetividad en la Movilidad en Transporte Urbano. Presented at 10th Congreso de Ingeniería del Transporte. Transporte Innovador y Sostenible de Cara al Siglo XXI, Granada, Spain, 2012.

26. Monzon, A., A. M. Pardeiro, and L. A. Vega. Reducing Car Trip and Pollutant Emissions Through Strategic Transport Planning in Madrid, Spain. In Highway and Urban Environment. Alliance For Global Sustainability Bookseries, Volume 12. Springer, Amsterdam, Netherlands, 2007, pp. 81-90.

27. Monzon, A., L. A. Vega, and M. E. López-Lambas. Potential to Attract Drivers Out of Their Cars in Dense Urban Areas. European Transport Research Review, Vol. 3, No. 3, 2011, pp. 129-137.

The Transportation Energy Committee peer-reviewed this paper. 